\title{
Interactions Between Myxobacteria, Plant Pathogenic Fungi, and Biocontrol Agents
}

\author{
C. T. Bull, USDA-ARS, 1636 E. Alisal St., Salinas, CA 93905; and K. G. Shetty and K. V. Subbarao, University \\ of California Davis, U.S. Agricultural Research Station, Salinas 93905
}

\section{ABSTRACT}

Bull, C. T., Shetty, K. G., and Subbarao, K. V. 2002. Interactions between myxobacteria, plant pathogenic fungi, and biocontrol agents. Plant Dis. 86:889-896.

Myxobacteria are soil dwelling gram-negative gliding bacteria that form fruiting bodies containing myxospores. Although myxobacteria produce a wide range of antibiotics and lytic enzymes that assist in their ability to prey on other microorganisms, their role in agriculture has received little attention. Myxococcus spp. were isolated from soils in organic and conventionally managed strawberry production and transplant fields in the absence of soil fumigation. Fumigation with methyl bromide and chloropicrin virtually eliminated these organisms from soil. However, soil fumigation had no effect on the frequency of isolation of Myхососсиs spp. from strawberry roots. Six Myхососсиs spp. were tested in vitro against eight soilborne plant pathogenic fungi (Cylindrocarpon spp., Fusarium oxysporum f. sp. apii, Phytophthora capsici, Pythium ultimum, Rhizoctonia spp., Sclerotinia minor, Verticillium albo-atrum, and V. dahliae) and against two fungal biological control agents (Gliocladium virens and Trichoderma viride). Phytophthora capsici, Pythium ultimum, Rhizoctonia spp., S. minor, and T. viride were completely inhibited by all of the Myxococcus spp. tested. F. oxysporum f. sp. apii was the least sensitive to the myxobacteria, and no inhibition occurred with some Myxococcus spp. Inhibition of the other fungi tested was variable. Myxococcus coralloides inhibited nearly all the fungi tested. The ability of bacterial biological control agents to produce antibiotics and other secondary metabolites determined whether or not they were lysed by myxobacteria. Secondary metabolite production regulated by gacS protected Pseudomonas fluorescens strain CHA0 from lysis by myxobacteria. More specifically, phenazine antibiotics produced by Pseudomonas aureofaciens strain 30-84 protected it from lysis.

Myxobacteria are gram-negative, unicellular bacteria with rod-shaped vegetative cells. They are unique among prokaryotes for using intercellular communication to engage in cooperative morphogenesis from which they produce fruiting bodies bearing resistant myxospores (5). Thick-walled myxospores are responsible for the survival of myxobacteria under unfavorable conditions such as desiccation, high temperature, and UV irradiation (17). Мyxobacteria have been found worldwide in many different types of soil (5). They inhabit the topsoil, and population estimates range from 2,000 to 450,000 cells per gram of soil (5). However, only a few authors reported their presence in agricultural soils $(5,24,29)$.

Myxobacteria specialize in the biodegradation of biomacromolecules and are considered micropredators because antibiotics and/or enzymes produced by myxobacteria kill microorganisms and lyse cells

Corresponding author: C. T. Bull

E-mail: cbull@pw.ars.usda.gov

Accepted for publication 22 April 2002.

Publication no. D-2002-0617-01R

This article is in the public domain and not copyrightable. It may be freely reprinted with customary crediting of the source. The American Phytopathological Society, 2002. from which biomacromolecules are then scavenged (5). Lytic metabolites include antibiotics, cell wall degrading enzymes, lipases, nucleases, polysaccharidases, and proteases (20). Some of these enzymes and antibiotics appear to be involved in the lysis of prey microbes as well as in autolysis or programmed cell death, which is simultaneous with myxospore development $(20,21)$.

Myxobacteria represent a rich source of bioactive secondary metabolites. Antibiotic compounds have been isolated from 55 and $95 \%$ of bacteriolytic and cellulolytic myxobacteria, respectively (18). More than 80 different basic structures and 350 structural variants have been identified from myxobacteria, placing myxobacteria in league with pseudomonads as abundant antibiotic producers (19). In contrast to pseudomonads and Bacillus spp., myxobacteria produce many different classes of antibiotics, including some that are rarely found as microbial secondary metabolites. Although many novel compounds have been isolated and are being evaluated for their clinical potential, the majority of compounds are macrocyclic lactone and lactam rings and linear cyclic peptides $(18,19)$. One familiar antibiotic of agricultural importance, pyrrolnitrin, has been isolated from the myxobacterial species Myxococcus fulvus, Corallococcus exiguous, and Cystobacter ferrugineus $(6,20)$.
Although pyrrolnitrin production by $\mathrm{Pseu}$ domonas fluorescens strain BL915 is required for control of damping-off of cotton caused by Rhizoctonia solani Kühn (7), the role of its production by myxobacteria in plant disease control has not been evaluated.

Although studies evaluating the role of secondary metabolites in predation of microorganisms by myxobacteria have been conducted, few studies have evaluated interactions between myxobacteria and plant pathogens. The genus Polyangium perforated and lysed the hyphae of $R$. solani and conidia of Cochliobolus miyabeanus Ito \& Kuribay (9). Hocking and Cook (8) found that the genus Sorangium could reduce damping-off of conifer seedlings and also lyse several fungi in culture. Additionally, Fusarium roseum was inhibited by fatty acids from Myxococcus xanthus (14). Despite their ability to produce a wide range of antibiotics and to prey on an array of microorganisms, the role of myxobacteria in plant health remains relatively unexplored.

The objectives of this research were to: (i) evaluate the presence of myxobacteria in agricultural soils of coastal California and on strawberry (Fragaria $\times$ ananassa Duchesne) roots; (ii) determine if fumigation with methyl bromide and chloropicrin influences myxobacterial populations; (iii) determine if myxobacteria influence the growth of important soilborne fungal plant pathogens and fungal biocontrol agents; and (iv) determine the role of secondary metabolite production and phenazine antibiotics in the protection of biological control agents from lysis by Myxococcus spp. Preliminary results of this research have been reported $(4,23)$.

\section{MATERIALS AND METHODS}

Media and microorganisms used. Bacterial and fungal strains used in this study are listed in Table 1. Cultures of myxobacteria were stored in casitone broth $(\mathrm{CY}$; $0.3 \%$ casitone, $0.1 \%$ yeast extract, $0.1 \%$ $\left.\mathrm{CaCl}_{2} \cdot \mathrm{H}_{2} \mathrm{O} ; 17\right)$ and glycerol $(1: 1)$ at $-80^{\circ} \mathrm{C}$. Myxobacteria were routinely cultured on CY agar (CYA) at 28 to $30^{\circ} \mathrm{C}$.

All bacterial strains other than myxobacteria were stored at $-80^{\circ} \mathrm{C}$ in a $1: 1$ solution of glycerol and nutrient broth (NB; Difco Laboratories, Detroit, MI) and were cultured on nutrient agar (NA; Difco Laboratories) prior to experiments.

All fungi except Pythium ultimum Trow were cultured on PDA and were stored on 
PDA slants at $4^{\circ}$ C. P. ultimum was cultured and stored on water agar (1.5\% agar). All chemicals were from Sigma Chemical Company (St. Louis, MO) unless otherwise stated.

Effects of fumigation on myxobacteria. Seven experiments were conducted at four locations in California to test the effect of soil fumigation on myxobacteria in the soil. The location, size, and number of replications for each experiment are given in Table 2. Experiments were established in the fall of 1999 and 2000 or the spring of 2000 and 2001 in fruit production or transplant fields, respectively. At all locations, methyl bromide and chloropicrin (MBC; Tri-CAL, Hollister, CA) was applied by shank injection on preformed beds or prior to bed formation. MBC and a nonfumigated control were included at all sites for comparison with either metham sodium (MS; Vapam HL formulation, AMVAC, Newport Beach, CA) or iodomethane and chloropicrin (MIC; Tomen Agro, San Francisco, CA). Fumigation rates and plant material used in these experiments are

Table 1. Microorganisms used in this research ${ }^{\mathrm{z}}$

\begin{tabular}{|c|c|c|c|}
\hline Organism & Strain & Information & Source \\
\hline \multicolumn{4}{|l|}{ Bacteria } \\
\hline \multicolumn{4}{|l|}{ Myxobacteria } \\
\hline Myxococcus coralloides & BS249 & & LS \\
\hline Myxococcus flavescens & 51243 & & ATCC \\
\hline Myxococcus fulvus & 23093 & & ATCC \\
\hline Myxococcus stipitatus & BS247 & & LS \\
\hline Myxососсиs virescens & 29616 & & ATCC \\
\hline Myxococcus xanthus $\mathrm{K}$ & 1622 & & 10 \\
\hline Myxococcus xanthus $\mathrm{L}$ & BS248 & & LS \\
\hline \multicolumn{4}{|c|}{ Biological control agents and derivatives } \\
\hline Pseudomonas aureofaciens & $30-84$ & $\mathrm{Phz}^{+} \mathrm{Rif}^{\mathrm{r}}$ wild type & 15 \\
\hline P. aureofaciens & $30-84 Z$ & $\mathrm{Phz}^{-} \mathrm{Rif}^{\mathrm{r}}$ phzB::lacZ of $30-84$ & 15 \\
\hline Pseudomonas fluorescens & CHA0 & Wild type & 25 \\
\hline P. fluorescens & CHA510 & gac $S:: \operatorname{Tn} 5$ mutant of CHA0 & 3 \\
\hline P. fluorescens & Pf-5 & Wild type & 12 \\
\hline \multicolumn{4}{|l|}{ Other bacteria } \\
\hline Escherichia coli & $\mathrm{DH} 5 \alpha$ & $\begin{array}{l}\text { F- recA1 gyrA96 relA1 } \\
\phi 80 l a c Z \Delta M 15\end{array}$ & 22 \\
\hline \multicolumn{4}{|l|}{ Fungi } \\
\hline \multicolumn{4}{|l|}{ Plant pathogens } \\
\hline Cylindrocarpon spp. & TJ 16 & & FM \\
\hline Fusarium oxysporum f. sp. apii & 47 & & KS \\
\hline Phytophthora capsici & GB 787b & & GB \\
\hline Pythium ultimum & S 11 & & FM \\
\hline Rhizoctonia spp. & 98Sort 12 & & FM \\
\hline Sclerotinia minor & Lettuce & & $\mathrm{KS}$ \\
\hline Sclerotinia sclerotiorum & Lettuce & & $\mathrm{KS}$ \\
\hline Verticillium albo-atrum & VaMs.102 & & $\mathrm{KS}$ \\
\hline Verticillium dahliae & VdFCa.21 & & KS \\
\hline \multicolumn{4}{|l|}{ Biological control agents } \\
\hline Coniothyrium minitans & $\mathrm{C}-102$ & & MG \\
\hline Gliocladium virens & G1-21 & & DF \\
\hline Talaromyces flavus & Tf1-M & & DF \\
\hline Trichoderma viride & $\mathrm{T}-5141$ & & $\mathrm{DF}$ \\
\hline
\end{tabular}

${ }^{\mathrm{z}}$ Strains are described in more detail in citations provided or they came from the collections of LS, Lawrance Shimkets; ATCC, American Type Culture Collection; KS, K. Subbarao; FM, F. Martin; GB, G. Browne; MG, M. Gerlagh; and DF, D. Fravel.

detailed in Table 2. All experiments were conducted under standard strawberry fruit or transplant production methods in growers' fields. Strawberry cultivar Camarosa was planted at all sites except at Watsonville (1999), where Aromas was planted. Each treatment had four or five replications depending on the experiment (Table 2). The intervals at which soils and roots were sampled are listed in Table 3. Treatments were arranged and analyzed as randomized complete blocks with blocking occurring on individual beds or areas of the field depending on the size of the plot.

Determination of the presence of myxobacteria in soils and on strawberry roots. Soil and root samples were taken from treated and untreated plots throughout the growing season (Table 3). Additionally, soil samples from five certified organic strawberry fields were evaluated. From each plot, 5 to 10 samples of soil (approximately $50 \mathrm{~g}$ each) were taken at a depth of 15 to $20 \mathrm{~cm}$. The samples were well mixed in a bucket, and a 50-g subsample was removed and transported back to the laboratory for processing. Field soil was air-dried for 3 weeks at room temperature $\left(23 \pm 1^{\circ} \mathrm{C}\right)$. Soils were then pulverized using a clean mortar and pestle. One gram of soil was placed in $10 \mathrm{ml}$ of sterile distilled water. Serial dilutions were made and were heated at $57^{\circ} \mathrm{C}$ for $30 \mathrm{~min}$. Aliquots were spread onto two plates of modified CY agar (CY-C10A; $1.0 \%$ casitone, $0.1 \%$ yeast extract, $0.1 \% \mathrm{CaCl}_{2} \cdot \mathrm{H}_{2} \mathrm{O}, 1.5 \%$ agar) amended with cycloheximide $(50 \mu \mathrm{g} / \mathrm{ml})$, nystatin $(50 \mu \mathrm{g} / \mathrm{ml})$, and vancomycin $(10$ $\mu \mathrm{g} / \mathrm{ml}$ ) (11). Presence of myxobacteria was determined in ten 1-g subsamples for each soil. In 1999, two subsamples were evaluated for each soil and each subsample was spread onto four CY agar plates. Presence or absence of myxobacteria on plates was recorded after 7 days incubation at $30^{\circ} \mathrm{C}$. Slow growing, swarming bacterial colonies were identified as myxobacteria.

A similar method was used to determine the presence of myxobacteria on roots of strawberry plants grown in fumigated and nonfumigated plots. Two plants were

Table 2. Rates of application of soil treatments on strawberry fields in California

\begin{tabular}{|c|c|c|c|c|c|c|c|}
\hline \multirow[b]{2}{*}{ Experiment $^{\mathrm{x}}$} & \multirow[b]{2}{*}{ Fumigation date } & \multirow[b]{2}{*}{$\begin{array}{c}\text { Type of } \\
\text { fumigation }\end{array}$} & \multirow[b]{2}{*}{$\begin{array}{c}\text { Size of individual } \\
\text { plots (ha) }\end{array}$} & \multirow[b]{2}{*}{$\begin{array}{l}\text { Number of } \\
\text { replications }\end{array}$} & \multicolumn{3}{|c|}{ Application rates of soil treatments ${ }^{w}$} \\
\hline & & & & & $\begin{array}{c}\mathrm{MBC} \\
(\mathrm{kg} / \mathrm{ha})\end{array}$ & $\begin{array}{c}\text { MS } \\
\text { (liters/ha) }\end{array}$ & $\begin{array}{c}\text { MIC } \\
(\mathbf{k g} / \mathrm{ha})\end{array}$ \\
\hline SJ (1) & $8 / 1999$ & Bed & $8.0 \times 10^{-4}$ & 5 & $476(67: 33)$ & 50 & $\mathrm{NT}^{\mathrm{y}}$ \\
\hline SJ $(2)^{z}$ & $8 / 1999$ & Bed & $2.0 \times 10^{-3}$ & 4 & $476(67: 33)$ & 50 & NT \\
\hline W (1) & 10/1999 & Bed & $8.5 \times 10^{-3}$ & 4 & $280(67: 33)$ & NT & NT \\
\hline W (2) & $7 / 2000$ & Bed & $1.3 \times 10^{-3}$ & 4 & $448(67: 33)$ & NT & $448(50: 50)$ \\
\hline B (1) & $4 / 2000$ & Flat & $4.5 \times 10^{-2}$ & 4 & $448(57: 43)$ & NT & $392(50: 50)$ \\
\hline B (2) & $4 / 2001$ & Flat & $4.5 \times 10^{-2}$ & 4 & $448(57: 43)$ & NT & $392(50: 50)$ \\
\hline$S(1)$ & $4 / 2000$ & Flat & $2.6 \times 10^{-2}$ & 4 & $397.6(67: 33)$ & NT & $392(50: 50)$ \\
\hline
\end{tabular}

${ }^{w}$ Numbers in parentheses designate rate of primary fumigant to chloropicrin. MBC, methyl bromide + chloropicrin; MS, metham sodium (42\% sodium methyldithiocarbamate); MIC, iodomethane + chloropicrin (95\% a.i.).

x SJ, San Jose; W, Watsonville; B, Ballico; S, Susanville. B and S are transplant fields, and SJ and W were fruit production fields. Numbers in parentheses represent independent experiments.

${ }^{\mathrm{y}} \mathrm{NT}=$ not tested.

${ }^{\mathrm{z}} \mathrm{SJ}$ (2) and W (2) were plots from larger experiments conducted by Husein Ajwa (University of California, Davis). 
evaluated from each plot on the dates specified in Table 3. Two roots (approximately $10 \mathrm{~cm}$ in length) from each plant were placed in $5 \mathrm{ml}$ of sterile distilled water. The sample was mixed (Touch Mixer Model 231, Fisher Scientific, Pittsburgh, PA) for $10 \mathrm{~s}$, sonicated for $60 \mathrm{~s}$ (Ultrasonic cleaner model 3210, Branson Ultrasonics Corp., Danbury, CT), and mixed again for $10 \mathrm{~s}$. Serial dilutions were made and were heated at $57^{\circ} \mathrm{C}$ for $30 \mathrm{~min}$. Aliquots of dilutions were spread onto six amended CY-C10A plates per plant. Presence or absence of myxobacteria was recorded after incubation at $30^{\circ} \mathrm{C}$ for 7 days.

The percentage of subsamples yielding myxobacteria was calculated for each plot. The percentages were arcsine transformed for data analysis, but the means of untransformed data are presented. Analysis of variance was conducted on transformed data followed by separation of means with Tukey's HSD using JMP (Version 4, SAS Institute, Cary, NC).

Inhibition of fungal plant pathogens or biological control agents by myxobacteria. The ability of myxobacteria to inhibit fungal plant pathogens and beneficial fungi was evaluated in vitro. Antibiosis by six myxobacteria was tested against 13 fungi (Table 1). Myxobacteria were inoculated in a $60-\mathrm{mm}$ ring on diluted casitone agar (dCTA) $\quad(0.2 \%$ casitone, $0.1 \%$ $\mathrm{MgSO}_{4} \cdot 7 \mathrm{H}_{2} \mathrm{O}, 1.5 \%$ agar) or on corn meal casitone agar (CCA; $1.7 \%$ corn meal agar, $0.5 \%$ casitone, $0.1 \% \mathrm{MgSO}_{4} \cdot 7 \mathrm{H}_{2} \mathrm{O}, 1.5 \%$ agar) in the case of Sclerotinia minor because this fungus grew poorly on dCTA. Myxobacterial cultures were incubated for 8 days at room temperature $\left(23 \pm 2{ }^{\circ} \mathrm{C}\right)$ prior to inoculation with fungi. Plugs of mycelium and agar (approximately 3-mmdiameter) were collected from 7- to 14day-old PDA plates using a metal cork borer and were placed on water agar for approximately $24 \mathrm{~h}$. Plugs were then transferred to the center of the myxobacterial ring. Plates with no myxobacteria were used as negative controls. Plates were incubated at room temperature $\left(23 \pm 2^{\circ} \mathrm{C}\right)$, and radial growth of the fungus was measured at $1,2,3,5,10,15,20,25$, and 30 days after inoculation with the fungi. The growth was measured in two directions, and the average of the two was used.

Treatments were arranged in a completely randomized design with three replications per treatment, and the experiments involving dCTA were conducted three times while those on CCA were conducted twice. Percent growth relative to the control was calculated for each treatment combination. Data were arcsine transformed for analysis, but untransformed data are presented. An analysis of variance procedure was used followed by separation of means with Tukey's HSD using JMP.

Interaction between myxobacteria and bacterial biological control agents. Experiments were also conducted to determine if myxobacteria could lyse or inhibit growth of bacterial biological control agents (BCA). BCAs and nearly isogenic antibiotic mutants were evaluated (Table 1). Escherichia coli DH5 $\alpha$ was used as a control. Myxobacteria were grown on dCTA agar. A loop of myxobacteria was used to make a turbid suspension of bacteria. A $20-\mu$ drop of the suspension was placed on dCTA. The plates were incubated for 7 days to allow the myxobacteria to establish a colony. Cells from single colonies of the BCA, their mutants, or the control were spread along a 4-cm strip starting $1 \mathrm{~cm}$ away from the outer growth of the myxobacterium. The size of the BCA strip and the distance lysed were measured after incubation for 4 days at room temperature. The size of the myxobacterial colony was also measured at that time. A preliminary experiment was conducted using seven myxobacterial strains. Myxococcus stipitatus, M. xanthus strain L, and $M$. fulvus were chosen to conduct rep- licated experiments because they represented the range of reactions that were seen in the preliminary experiment. The role of phenazine in myxobacterial-BCA interactions was evaluated by comparing lysis of Pseudomonas aureofaciens strains 30-84 and $30-84 \mathrm{Z}$, a phenazine producer and mutant, respectively. The experiment was a $3 \times 3$ factorial arranged in a completely randomized design (CRD) with three replicate plates per treatment combination.

The role of secondary metabolites regulated by the gacA/gacS two-component regulatory system in Pseudomonas fluorescens-myxobacteria interactions was evaluated by comparing lysis of a gacS mutant and two P. fluorescens strains CHAO and Pf-5 with intact regulatory systems. This experiment was designed and analyzed analogously to the first experiment except that it was a $4 \times 3$ factorial.

Each experiment was conducted at least twice. Percent lysis data were arcsine transformed for analysis, but untransformed data are presented. An analysis of variance procedure was used followed by separation of means with Tukey's HSD using JMP.

\section{RESULTS}

Effect of soil fumigation on myxobacteria. Swarming bacterial colonies growing slowly on antibiotic containing media (amended CY-C10A) were isolated from all strawberry fields sampled (Table 3). For approximately $10 \%$ of the identified strains, fruiting body formation was observed to confirm that these strains were myxobacteria. Representative isolates were stored for further study. Myxobacteria were present in conventionally managed soils (controls) as well as in all five certified organic strawberry production fields tested, where no fumigation had occurred for 5 years or more (data not shown).

Fumigation of soil with MBC eliminated myxobacteria detectable from available

Table 3. Influence of soil fumigation on detection of myxobacteria

\begin{tabular}{|c|c|c|c|c|c|c|c|}
\hline \multirow[b]{2}{*}{ Experiment $^{\mathrm{x}}$} & \multirow[b]{2}{*}{ Fumigation date } & \multirow[b]{2}{*}{ Sample type } & \multirow[b]{2}{*}{ Sample date } & \multicolumn{4}{|c|}{ Percent recovery $^{w}$} \\
\hline & & & & Control & $\mathrm{MBC}^{\mathbf{y}}$ & MS & MIC \\
\hline \multirow[t]{3}{*}{ SJ (1) } & $8 / 1999$ & Soil & $10 / 1999$ & $100 \mathrm{a}$ & $0 \mathrm{~b}$ & $100 \mathrm{a}$ & $\mathrm{NT}^{\mathrm{z}}$ \\
\hline & & Soil & $8 / 2000$ & $100 \mathrm{a}$ & $0 \mathrm{~b}$ & $100 \mathrm{a}$ & NT \\
\hline & & Roots & $6 / 2000$ & $70 \mathrm{a}$ & $10 \mathrm{a}$ & $50 \mathrm{a}$ & NT \\
\hline \multirow[t]{3}{*}{ SJ (2) } & $8 / 1999$ & Soil & $11 / 1999$ & $87.5 \mathrm{a}$ & $0 \mathrm{~b}$ & $87.5 \mathrm{a}$ & NT \\
\hline & & Soil & $8 / 2000$ & $75 \mathrm{a}$ & $0 \mathrm{~b}$ & $100 \mathrm{a}$ & NT \\
\hline & & Roots & $7 / 2000$ & $75 \mathrm{a}$ & $50 \mathrm{a}$ & $75 \mathrm{a}$ & NT \\
\hline \multirow[t]{3}{*}{ W (1) } & $10 / 1999$ & Soil & $11 / 1999$ & $87.5 \mathrm{a}$ & $0 \mathrm{~b}$ & NT & NT \\
\hline & & Soil & $9 / 2000$ & $87.5 \mathrm{a}$ & $25 \mathrm{~b}$ & NT & NT \\
\hline & & Roots & $6 / 2000$ & $75 \mathrm{a}$ & $62.5 \mathrm{a}$ & NT & NT \\
\hline W (2) & $7 / 2000$ & Soil & $8 / 2000$ & $52.5 \mathrm{a}$ & $2.5 \mathrm{~b}$ & NT & $0 \mathrm{~b}$ \\
\hline B (1) & $4 / 2000$ & Soil & $5 / 2000$ & $37.5 \mathrm{a}$ & $0 \mathrm{a}$ & NT & $12.5 \mathrm{a}$ \\
\hline B (2) & $4 / 2001$ & Soil & $4 / 2001$ & $50 \mathrm{a}$ & $0 \mathrm{~b}$ & NT & $25 \mathrm{a}$ \\
\hline S (1) & $4 / 2000$ & Soil & $4 / 2000$ & $17.5 \mathrm{a}$ & $0 \mathrm{a}$ & NT & $2.5 \mathrm{a}$ \\
\hline
\end{tabular}

${ }^{\mathrm{w}}$ Arcsine transformed data were analyzed. Percent data for a given date and location followed by the same letter are not significantly different at the $P=$ 0.01 level according to Tukey's HSD.

x SJ, San Jose; W, Watsonville; B, Ballico; S, Susanville. B and S are transplant fields, and SJ and W were fruit production fields. Numbers in parentheses designate individual trials at a particular location.

y MBC, methyl bromide + chloropicrin; MS, metham sodium (sodium methyldithiocarbamate); MIC, iodomethane + chloropicrin.

${ }^{\mathrm{z}} \mathrm{NT}=$ not tested. 
methods (Table 3). In six out of seven experiments, myxobacteria were not detected in MBC fumigated plots or were detected in only $2.5 \%$ of the samples evaluated within 1 month following fumigation. In contrast, myxobacteria were detected in 17.5 to $100 \%$ of the nonfumigated control plots. MBC significantly reduced the frequency of myxobacteria recovery from soil samples in five of the seven experiments $(P=0.01)$. In the remaining two experiments (Ballico, 2000; Susanville, 2000), the control plots had low levels of myxobacteria present. In nonfumigated plots, 17.5 to $37.5 \%$ of samples had myxobacteria compared with 50 to $100 \%$ for experiments where the differences were significant.

In two out of three experiments for which soil was also sampled at the end of the fruiting season, myxobacteria were not detected in fumigated plots approximately 1 year after fumigation. However, in one experiment, $25 \%$ of samples from MBC fumigated plots had myxobacteria at the end of the season although none were detected 1 month after fumigation. In this experiment, the frequency of myxobacteria detection in MBC treated plots was significantly lower $(P=0.01)$ than in nonfumigated plots. Metam sodium (MS) did not reduce the percentage of samples from which myxobacteria were recovered relative to nonfumigated controls (Table 3 ).

Although the mean percentage of samples with myxobacteria was always lower in MIC-treated plots than in nonfumigated controls, the difference was only significant in the trial where no myxobacteria were detected in samples from the MIC fumigated plots. Two of the three experiments in which MIC did not significantly reduce myxobacteria incidence were the same experiments in which MBC did not reduce recovery and the frequency of recovery from control plots was low.

Although myxobacteria were detected less frequently in MBC fumigated soils, there was no difference in the recovery of myxobacteria from roots of plants grown
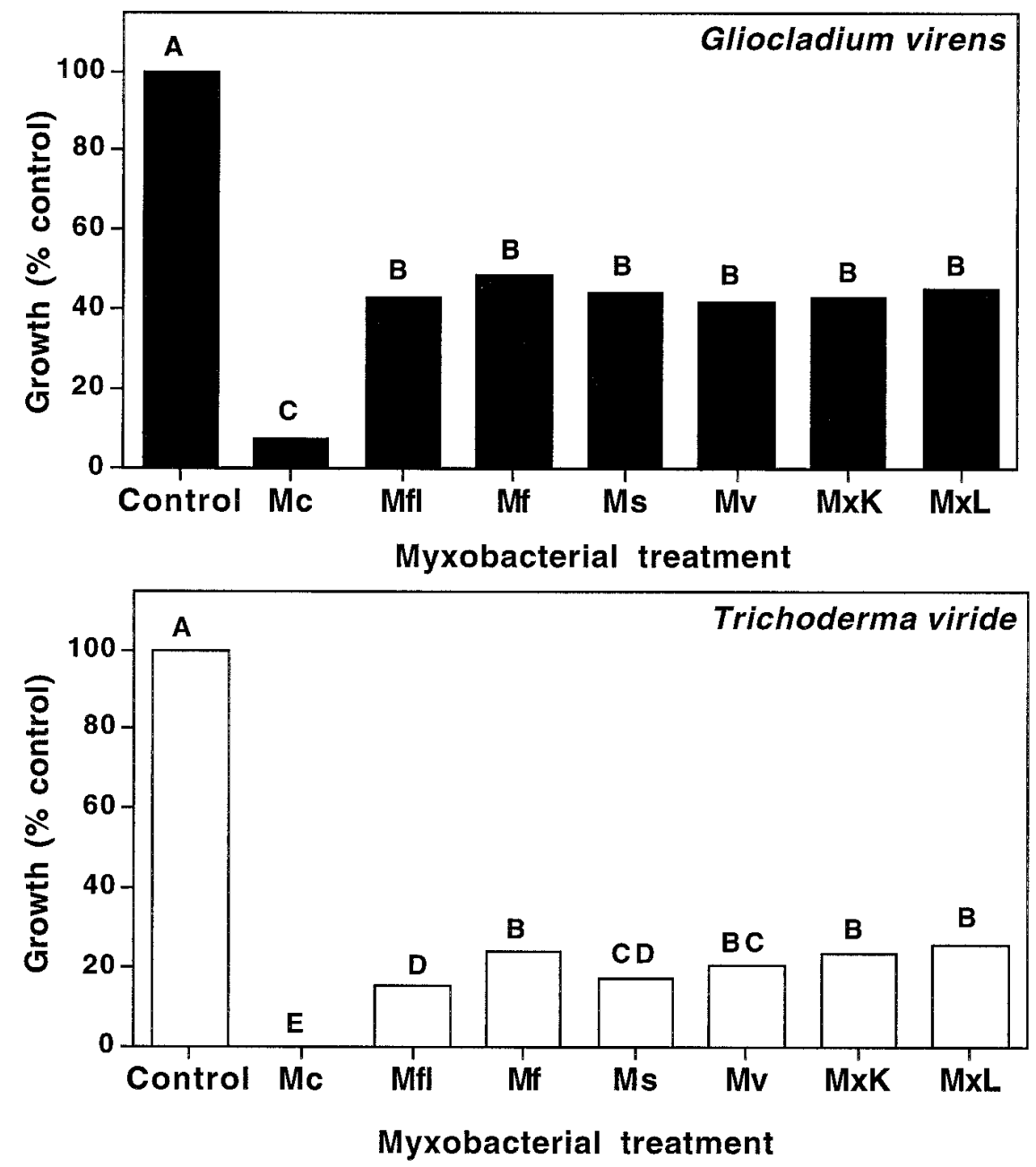

Fig. 1. Inhibition of biological control fungi by myxobacteria. Bars represent the mean diameter of fungal growth expressed as a percentage of growth of the controls in three experiments with three replications. Arcsine transformed data were analyzed after pooling for three experiments. Bars labeled with the same letter are not significantly different $(P>0.05)$ according to Tukey's HSD test. Myxobacteria: Mc, Myxococcus coralloides; Mfl, M. flavescens; Mf, M. fulvus; Ms, M. stipitatus; Mv, M. virescens; MxK, M. xanthus strain K; MxL, M xanthus strain L. in fumigated or nonfumigated soils (Table $3)$. In two of three experiments, myxobacteria were isolated from $50 \%$ or more of roots grown in $\mathrm{MBC}$ fumigated soil. In one experiment, myxobacteria were recovered from only $10 \%$ of roots of plants grown in MBC fumigated soil, but this was not significantly different $(P=0.06)$ from plants grown in nonfumigated soil.

Inhibition of fungal pathogens and fungal biological control agents by myxobacteria. In all experiments, there was a significant interaction between the myxobacteria strains and the test strains (fungal pathogens and biological control agents $[P=0.01])$. Therefore, no generalizations could be made about the interactions of all myxobacteria and fungi tested. Data are presented for each individual pathogen or fungal biological control agent evaluated (Figs. 1 and 2). Because interactions between experiments and myxobacterial treatments were not significant $(P=$ 0.33 ) and there was homogeneity of variance from the three experiments according to Bartlett's test (0.99), pooled results are presented (Figs. 1 and 2).

Trichoderma viride and Gliocladium virens were the only biological control fungi that grew well on the media used. Talaromyces flavus and Coniothyrium minitans grew less than $2.9 \mathrm{~cm}$ on dCTA. Both of these fungi grew faster on CCA but were not evaluated further. Myхососcus coralloides completely inhibited growth of $T$. viride (Fig. 1), and inhibition (53 to $85 \%$ ) by other myxobacteria was significant $(P=0.0001)$.

$G$. virens was slightly less sensitive to the myxobacteria (Fig. 1). Although $M$. coralloides almost completely inhibited (92 to $100 \%$ ) G. virens, inhibition by the other myxobacteria was lower (54 to $80 \%)$, albeit significant $(P=0.0001)$.

Myxobacteria significantly inhibited $S$. minor (on CCA), Pythium ultimum, Rhizoctonia spp., and Phytophthora capsici $(P=0.0001)$. Pythium ultimum was completely inhibited by all the myxobacteria in all experiments (Fig. 2). S. minor and Rhizoctonia spp. were completely inhibited by the Myxococcus spp. in most cases. Although $S$. minor produced sclerotia in control plates, when cocultured with myxobacteria, no sclerotia were produced (data not shown). In most experiments, myxobacteria inhibited these fungi completely, but there were individual examples in which the inhibition was not complete. For example, only 63 and $72 \%$ inhibition of $P$. capsici was achieved by $M$. flavescens and M. fulvus, respectively, in one experiment each, whereas complete inhibition was observed in other experiments.

Verticillium dahliae, $V$. albo-atrum, Cylindrocarpon spp., and Fusarium oxysporum f. sp. apii were less sensitive to the myxobacteria. Inhibition by $M$. coralloides was not complete and ranged from 
66 to $90 \%$ (Fig. 2). Although significant, inhibition of $V$. dahliae was only 19 to $48 \%$. For $V$. albo-atrum and Cylindrocarpon spp., inhibition ranged between 22 and $59 \%$ and 13.6 and $36.1 \%$, respectively. Although M. coralloides almost completely inhibited all other pathogens, inhibition of $F$. oxysporum f. sp. apii, was only 56 to $58 \%$ (Fig. 2) and was significantly lower than for all the other pathogens tested $(P=0.0001)$.

In vitro interactions between myxobacteria and bacterial biological control agents. In all experiments, there was a significant interaction $(P=0.0001)$ between the predator strains (myxobacteria) and the test strains (BCAs and mutants). Therefore data are presented for each individual myxobacterial strain tested (Figs. 3 and 4).

The phenazine producer, Pseudomonas aureofaciens 30-84 was not lysed by $M$. stipitatus but in contrast $M$. stipitatus was inhibited by strain $30-84$ resulting in a negative mean value for lysis (Fig. 3). Pseudomonas aureofaciens strain 30-84Z is a near-isogenic mutant of strain 30-84 which does not produce phenazines, and it was lysed by $M$. stipitatus. M. fulvus and M. xanthus strain L lysed Pseudomonas aureofaciens 30-84 in all experiments. Lysis of strain $30-84$ by $M$. fulvus was significantly less than its phenazine minus mutant 30-84Z. Results with M. xanthus strain L were variable (Fig. 3). M. xanthus strain L lysed the mutant to a greater degree than the wild type in only one of three experiments (data shown for two experiments). E. coli DH5 $\alpha$ served as an adequate control in all of the experiments, and it was lysed by each myxobacterium tested (Figs. 3 and 4).
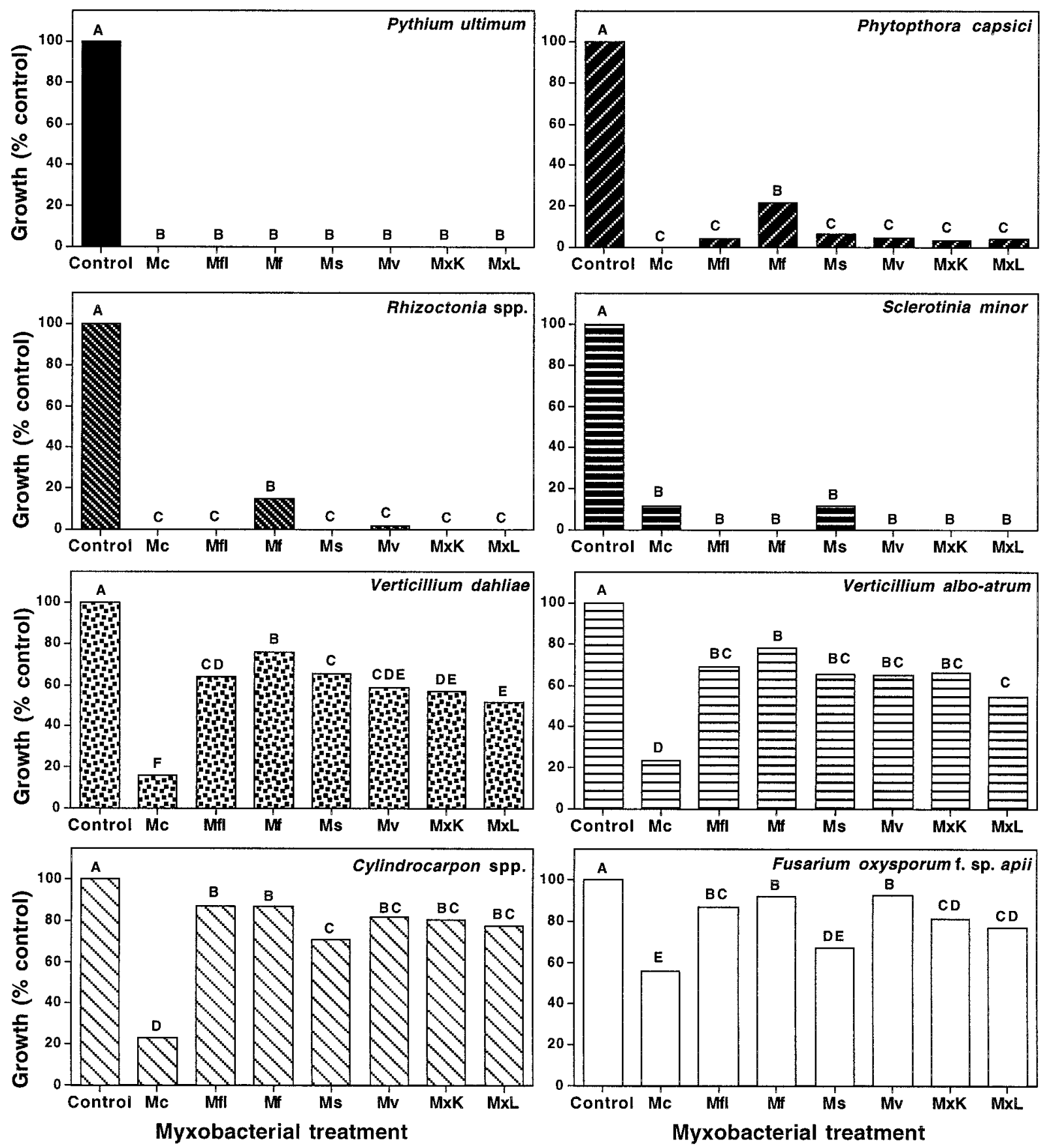

Fig. 2. Inhibition of fungal plant pathogens by myxobacteria. Bars represent the mean diameter of fungal growth expressed as a percentage of growth of the controls in three experiments with three replications. Arcsine transformed data were analyzed after pooling the three experiments. Bars labeled with the same letter are not significantly different $(P>0.05)$ according to Tukey's HSD test. Myxobacteria: Mc, Myxococcus coralloides; Mfl, M. flavescens; Mf, M. fulvus; Ms, M. stipitatus; Mv, M. virescens; MxK, M. xanthus strain K; MxL, M xanthus strain L. 
Pseudomonas fluorescens strains CHA0 and PF-5 inhibited the growth of the myxobacteria in all experiments although they were applied after the myxobacteria (Fig. 4). Myxococcus spp. did not lyse these two strains in any of the experiments. E. coli strain DH5 $\alpha$ and strain CHA510, a gacS mutant of strain CHA0, did not inhibit the myxobacteria. Additionally, the gacS mutant, CHA510, was lysed by the myxobacterium although the wild-type strain was not. Strains DH5 $\alpha$ and CHA510 were lysed to the same extent by $M$. xanthus and M. fulvus, but strain CHA510 was lysed to a lesser extent by M. stipitatus than was strain DH5 $\alpha$.

\section{DISCUSSION}

Although over 100 publications have documented the occurrence of myxobacteria in soils of moderate $\mathrm{pH}$ and salinity (5), their presence in agricultural soils has rarely been reported $(8,9,24,29)$. In this study, myxobacteria were isolated from strawberry transplant and production fields in California. Their presence in both organically managed and conventionally managed fields in the absence of soil fumigation suggests that they may be common in nonfumigated agricultural fields.

Fumigation with $\mathrm{MBC}$ is a common practice to control soilborne diseases and weeds in strawberry production fields (27).

\section{Experiment 1}

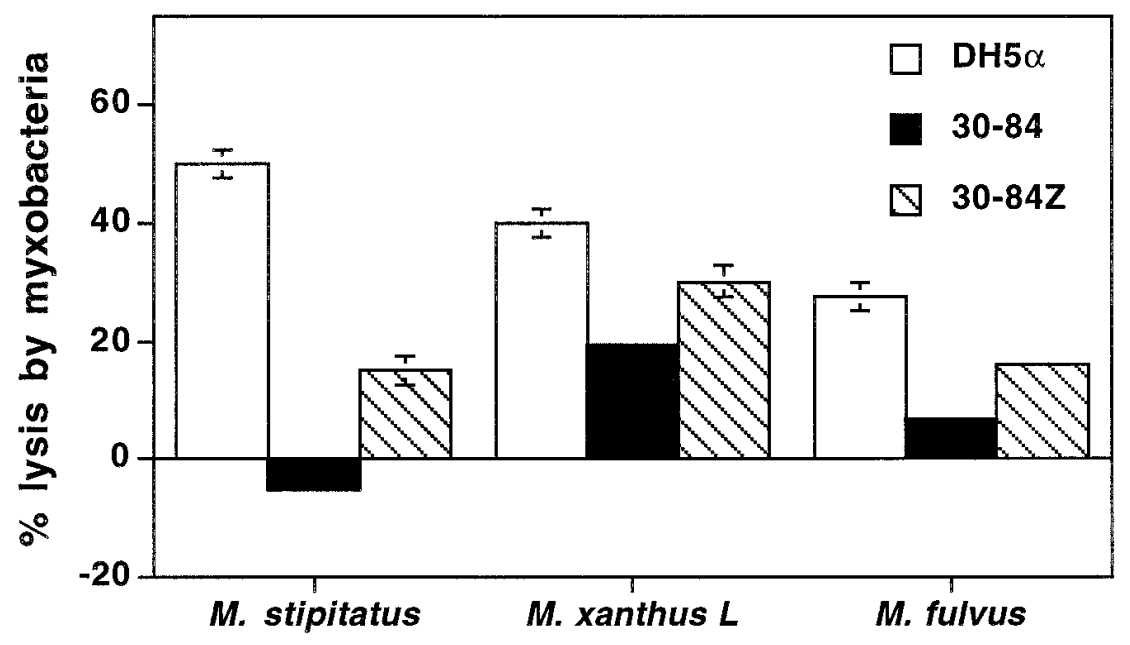

Predator strain

\section{Experiment 2}

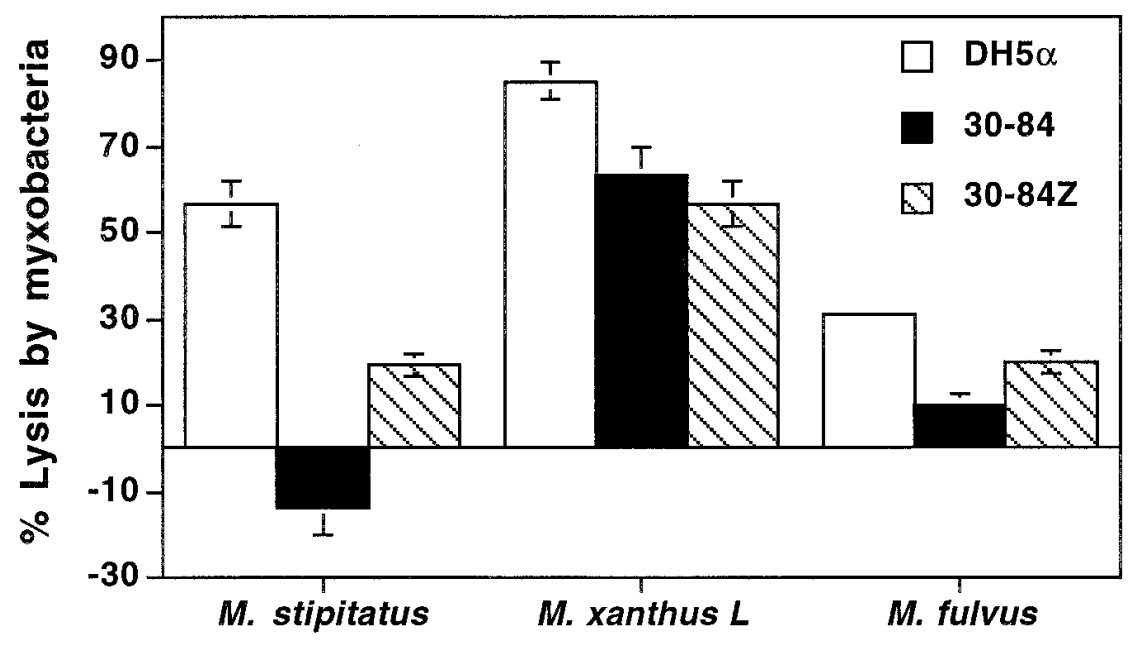

Predator strain

Fig. 3. Role of phenazine in protection of Pseudomonas aureofaciens 30-84 against predation by myxobacteria. Bars represent the mean length of a bacterial colony lysed by myxobacteria expressed as a percentage of growth. Negative responses indicate the percent inhibition of the myxobacterial colony by prey strains. Arcsine transformed data were analyzed separately for each experiment. Within each experiment, bars labeled with the same letter are not significantly different $(P>0.05)$ according to Tukey's HSD test. Standard deviations around the means are represented by vertical lines above the bars, and treatments lacking a vertical line had a standard deviation of 0 . Prey strains: Escherichia coli DH5 $\alpha$, Pseudomonas aureofaciens 30-84 (phenazine producer), P. aureofaciens 30$84 \mathrm{Z}$ (phenazine minus mutant).

Methyl bromide is a general biocide that reduces soilborne diseases caused by plant pathogens $(27,28,30)$. We initially speculated that methyl bromide might not significantly reduce myxobacterial populations because methyl bromide is not as efficacious a bactericide or actinomyticide as it is a fungicide (26) and myxobacteria produce resistant spores. In spite of resistant resting structures, myxobacteria appear to be sensitive to MBC fumigation and fumigation with alternatives, although the level of sensitivity of myxospores to fumigants remains to be tested.

Previous studies (8) indicated that fumigated peat is colonized to a higher level than nonfumigated peat by introduced myxobacteria. However, myxobacteria were not detected in fumigated soils months after fumigation, suggesting that recolonization of the soil does not occur quickly after fumigation. Nonetheless, myxobacteria were detected in the rhizosphere of strawberry plants grown in fumigated soils even though they were not detected in the fumigated soils in which the plants were grown. Isolation of myxobacteria from strawberry roots in nonfumigated soil was likely since the bacteria were present in the soil. However, this is the first documentation of the isolation of myxobacteria from the rhizosphere of strawberry and perhaps of any agricultural food crop. Fruiting bodies of myxobacteria have previously been detected on cotton (1) and pine roots (8).

The source of the myxobacteria in the rhizosphere of strawberries grown in fumigated soils is unknown. Their presence on strawberry roots may have been due to an increase of residual populations in the presence of a large prey population. In general, there are 10 to 100 times more bacteria present per gram of soil in the rhizosphere of plants than in the bulk soil. Larger populations of myxobacteria are isolated in habitats where larger populations of their prey are found (5). High rhizosphere populations of introduced myxobacteria were detected in other studies (8). This indicates that surviving myxobacteria populations may increase in the rhizosphere after fumigation. Alternatively, myxobacteria may also be introduced on the roots of strawberry transplants. The source and role of myxobacteria on roots of strawberry in fumigated soils needs further study.

Estimates for populations of myxobacteria in the soil vary greatly because of the soil types tested and assay methods employed (5). Even under ideal conditions, myxobacterial populations are difficult to estimate using standard plating techniques. Myxobacterial cells produce a sticky slime for gliding movement which makes individual vegetative cells difficult to separate. Molecules formed on the outside of cells help them to stick together during fruiting body formation and again prevent individ- 
ual cells from being separated (5). Furthermore, under low nutrient conditions, fimbria are produced which bind spores and cells together $(5,17)$. Even under laboratory conditions, these characteristics make quantitative evaluation using standard plate counting techniques a difficult proposition limiting the study of myxobacteria ecology. We therefore chose to describe the frequency of detection from a given soil. Characterization of populations using this technique allows detection of large changes in populations but may miss more subtle changes. Using this method, we demonstrated that fumigation with
MBC and some alternative fumigants significantly reduced the populations of myxobacteria. We used an isolation medium that was relatively specific for the detection of Myxococcus spp. (11), because Myxococcus spp. are predators of fungi and bacteria that may have significant roles in agroecosystems. A simpler and more accurate enumeration technique for any of the myxobacteria would greatly improve the ability to study their ecology.

Documenting the presence of myxobacteria in agricultural soils is the first step in describing their potential role in agroecosystems. One potential role for myxobacte-

\section{Experiment 1}

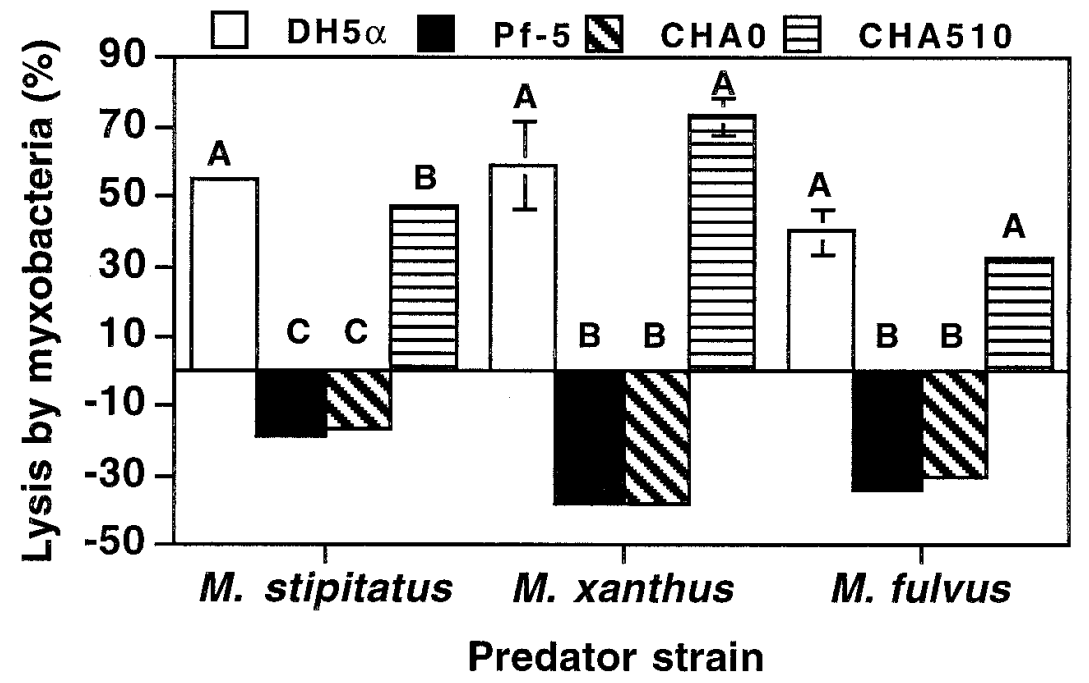

Experiment 2

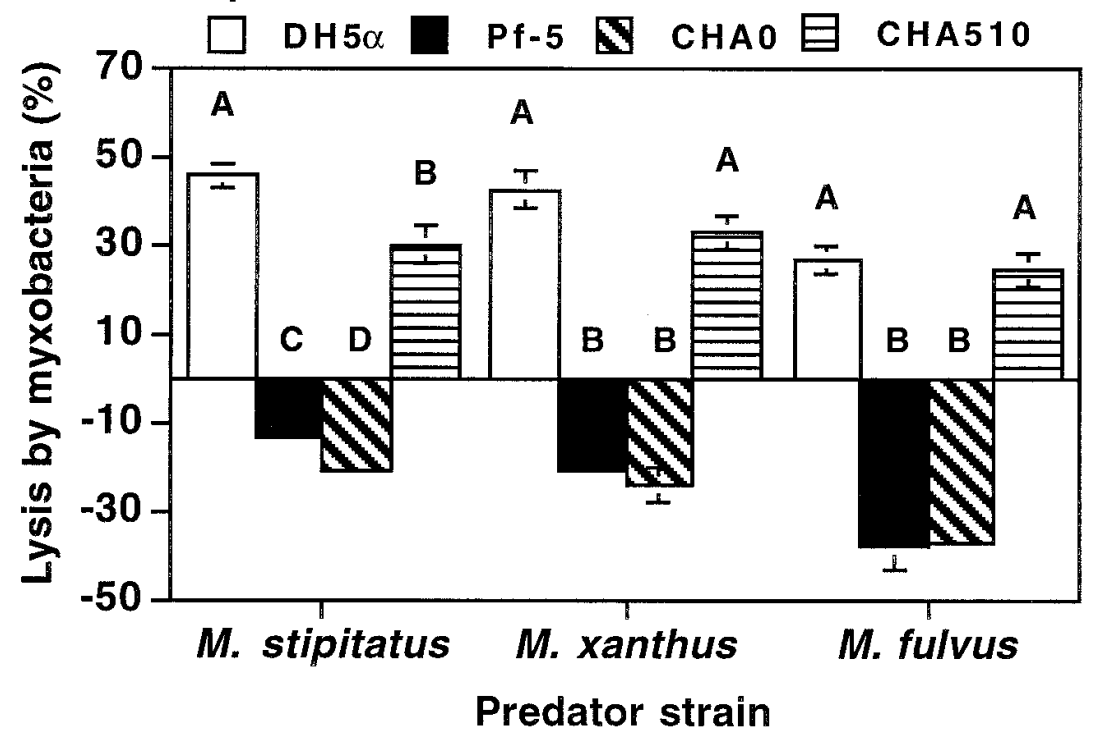

Fig. 4. Inhibition of myxobacteria by antibiotic producing bacteria, Pseudomonas fluorescens strains CHA0 and Pf-5. Bars represent the mean length of a bacterial colony lysed by myxobacteria expressed as a percentage of growth. Negative responses indicate the percent inhibition of the myxobacterial colony by prey strains. Arcsine transformed data were analyzed separately for each experiment. Within each experiment, bars labeled with the same letter are not significantly different $(P>$ 0.05 ) according to Tukey's HSD test. Standard deviations around the means are represented by vertical lines above the bars, and treatments lacking a vertical line had a standard deviation of 0 . Prey strains: Escherichia coli DH5 $\alpha$, Pseudomonas fluorescens Pf-5 (produces multiple antibiotics), $P$. fluorescens CHA0 (produces multiple antibiotics), CHA510 (gacS mutant no longer producing antibiotics and other secondary metabolites regulated by gacA/gacS two component system).

ria is regulating populations of bacteria and fungi in the soil. Myxobacteria inhibit or lyse several important soilborne plant pathogens, including $R$. solani, $C$. miyabeanus, Pythium intermedium, $F$. oxysporum, and $F$. solani $(8,9)$. We have demonstrated that soilborne fungal pathogens of strawberry and other economically important crops are also inhibited in vitro by myxobacteria. Myxobacteria significantly inhibited Pythium ultimum, Rhizoctonia spp., Cylindrocarpon spp., Phytophthora capsici, V. albo-atrum, and V. dahliae. Only one myxobacterium, $M$. coralloides, inhibited $F$. oxysporum f. sp. apii. In a previous study, Pythium was found to be the most sensitive to myxobacterial lysis, followed by Rhizoctonia, and lastly $F$. oxysporum (8). We also observed that $P y$ thium ultimum was completely inhibited by myxobacteria, Rhizoctonia was slightly less sensitive, and $F$. oxysporum f. sp. apii was virtually resistant to myxobacteria. In addition to the plant pathogens, the biocontrol fungi $T$. viride and $G$. virens were significantly inhibited by the myxobacteria. The potential for myxobacteria to inhibit plant pathogens or interrupt biological control in situ needs further study.

Many antibiotic producing fluorescent pseudomonads are found in the rhizosphere of plants and have been used in an augmentative approach to control soilborne diseases of plants (2). In this study, we have demonstrated that secondary metabolites produced by two species of Pseudomonas are important in the protection of the producer strains from lysis by myxobacteria in vitro. Although many soilinhabiting bacteria produce secondary metabolites in vitro, which inhibit other soil-dwelling microorganisms, this is the first report of secondary metabolites being involved in protection from predation.

Two similar strains, Pseudomonas fluorescens strains $\mathrm{CHA} 0$ and $\mathrm{Pf}-5$, produce the antibiotics 2,4-diacetyl-phloroglucinol, pyoluteorin, and pyrrolnitrin, as well as the biocide hydrogen cyanide $(3,12)$. Antibiotics produced by these strains as well as other characterized and potentially uncharacterized secondary metabolites are regulated by the two-component regulatory system coded for by gacA and gacS. These strains inhibited the growth of all of the myxobacteria tested even though they were inoculated 7 days after the myxobacterial strains. Although myxobacteria commonly prey on bacteria and lyse them to use nutrients contained in their cells, these two strains were not lysed by any of the myxobacteria tested. A mutation in the gacS gene of CHA0 results in the loss of secondary metabolite production (3). The gacS mutant, CHA510, was lysed and did not inhibit the myxobacteria, indicating that metabolites regulated by gacS are involved in inhibition of myxobacteria and protection of strain CHA0. Use of near-isogenic strains with mutations in biosynthetic 
genes for individual antibiotics and secondary metabolites will help determine which metabolites are important in the inhibition of myxobacteria by strains $\mathrm{CHA} 0$ and Pf-5.

In order to evaluate the role of a particular class of antibiotics, we evaluated nearisogenic strains of Pseudomonas aureofaciens, one producing phenazines and a mutant which did not. Phenazines have previously been shown to play a role in the inhibition of fungal pathogens (16) as well as in microbial competition and survival of fluorescent pseudomonads in soil (13). Phenazine production mutants decline in natural soil more rapidly than do wild-type strains, and this antibiotic was therefore hypothesized to play a role in long-term survival. This study indicates that phenazines may play a role in long-term survival of strain 30-84 by protecting the strain from predation by myxobacteria. Further study of the interactions between myxobacteria and other soil inhabitants will be needed to determine if secondary metabolites protect these strains from predation in situ.

Myxobacteria produce $3.5 \%$ of all the known secondary metabolites produced by bacteria, and novel metabolites are being discovered from individual strains at a rapid pace (18). These organisms were present in soils used for strawberry production and in the strawberry rhizosphere. Additionally, they inhibited economically important soilborne pathogens in vitro. Despite these useful characteristics, the role of myxobacteria in agricultural soils remains to be determined because adequate ecological methods are not available for these organisms. While these organisms are culturable, they remain recalcitrant. Research is needed to improve enumeration and culturing methods of these organisms in order to study the effect of these organisms on plant pathogens and biological control agents in situ.

\section{ACKNOWLEDGMENTS}

We thank L. S. Pierson and L. M. Gorski for reviews of the manuscript, and Thi Duong and Micheal Abarca for technical collaboration. This research was supported in part by grant 200005381 of the USDA/CSREES Methyl Bromide Transitions Program. Mention of trade names or commercial products in this publication is solely for the purpose of providing specific information and does not imply recommendation or endorsement by the U.S. Department of Agriculture.

\section{LITERATURE CITED}

1. Agnihothrudu, V., Barua, G. C. S., and Barua, K. C. 1959. Occurrence of Chondromyces in the rhizosphere of plants. Indian Phytopathol. 12:158-160.

2. Bull, C. T. 2001. Biological Control. Pages 130-135 in: Encyclopedia of Plant Pathology. O. Maloy and T. Murray, eds. John Wiley \& Sons, New York.

3. Bull, C. T., Duffy, B., Voisard, C., Défago, G., Keel, C., and Haas, D. 2001. Characterization of spontaneous gacS and gacA regulatory mutants of Pseudomonas fluorescens biocontrol strain CHA0. Antonie van Leeuwenhoek 79:327-336.

4. Bull, C. T., Shetty, K. G., and Subbarao, K. V. 2000. Interactions between myxobacteria, plant pathogenic fungi and biocontrol agents. Pages 94 in: Proc. Annu. Int. Res. Conf. Methyl Bromide Alternatives Emissions Reductions, Orlando, FL.

5. Dawid, W. 2000. Biology and global distribution of myxobacteria in soils. FEMS Microbiol. Rev. 24:403-427.

6. Gerth, K., Trowitzsch, W., Wray, V., Höfle, G., Irschik, H., and Reichenbach, H. 1982. Pyrrolnitrin from Myxococcus fulvus (Myxobacterales). J. Antibiot. 35:1101-1103.

7. Hill, D. S., Stein, J. I., Torkewitz, N. R., Morse, A. M., Howell, C. R., Pachlatko, J. P., Becker, J. O., and Ligon, J. M. 1994. Cloning of genes involved in the synthesis of pyrrolnitrin from Pseudomonas fluorescens and role of pyrrolnitrin synthesis in biological control of plant disease. Appl. Environ. Microbiol. 60:78-85.

8. Hocking, D., and Cook, F. D. 1972. Myxobacteria exert partial control of damping-off and root disease in container-grown tree seedlings. Can. J. Microbiol. 18:1557-1560.

9. Homma, Y. 1984. Perforation and lysis of hyphae of Rhizoctonia solani and conidia of Cochliobolus miyabeanus by soil myxobacteria. Phytopathology 74:1234-1239.

10. Kaiser, D. 1979. Social gliding is correlated with the presence of pili in Myxococcus xanthus. Proc. Natl. Acad. Sci. USA 76:59525956.

11. Karwowski, J. P., Sunga, G. N., Kadam, S., and McAlpine, J. B. 1996. A method for the selective isolation of Myxococcus directly from soil. J. Indust. Microbiol. 16:230-236.

12. Kraus, J., and Loper, J. E. 1992. Lack of evidence for a role of antifungal metabolite production by Pseudomonas fluorescens Pf-5 in biological control of Pythium damping-off of cucumber. Phytopathology 82:264-271.

13. Mazzola, M., Cook, R. J., Thomashow, L. S., Weller, D. M., and Pierson, L. S., III. 1992. Contribution of phenazine antibiotic biosynthesis to the ecological competence of fluorescent pseudomonads in soil habitats. Appl. Environ. Microbiol. 58:2616-2624.

14. Norén, B., and Odham, G. 1973. Antagonistic effects of Myxococcus xanthus on fungi: II. Isolation and characterization of inhibitory lipid factors. Lipids 8:573-583.

15. Pierson, L. S., III, Keppenne, V. D., and Wood, D. W. 1994. Phenazine antibiotic biosynthesis in Pseudomonas aureofaciens 30-84 is regulated by $\mathrm{PhzR}$ in response to cell density. J. Bacteriol. 176:3966-3974.

16. Pierson, L. S., III, and Thomashow, L. S.
1992. Cloning and heterologous expression of the phenazine biosynthetic locus from Pseudomonas aureofaciens 30-84. Mol. PlantMicrobe Interact. 5:330-339.

17. Reichenbach, H., and Dworkin, M. 1992. The myxobacteria. Pages 3416-3487 in: The Prokaryotes. A. Balows, H. G. Trüper, M. Dworkin, W. Harder, and K.-H. Schleifer, eds. Springer Verlag, Berlin.

18. Reichenbach, H., and Hölfe, G. 1993. Biologically active secondary metabolites from myxobacteria. Biotech. Adv. 11:219-277.

19. Reichenbach, H., and Höfle, G. 1998. Myxobacteria as producers of secondary metabolites. Pages 149-179 in: Drug Discovery from Nature. S. Grabley and R. Thiericke eds. Springer Verlag, Berlin.

20. Rosenberg, E., and Varon, M. 1984. Antibiotics and Lytic Enzymes. Pages 109-125 in: Myxobacteria: Development and Cell Interactions. E. Rosenberg, ed. Springer Verlag, New York.

21. Rosenbluh, A., and Rosenberg, E. 1993. Developmental lysis and autocides. Pages 213-233 in: Myxobacteria II. M. Dworkin and D. Kaiser, eds. ASM, Washington, DC.

22. Sambrook, J., Fritsch, E. F., and Maniatis, T. 1989. Molecular Cloning: A Laboratory Manual, 2nd ed. Cold Spring Harbor Laboratory, Cold Spring Harbor, NY.

23. Shetty, K. G., Subbarao, K. V., and Bull, C. T. 2000. Effects of myxobacteria on plant pathogenic fungi and biocontrol agents. Phytopathology 90:S72.

24. Singh, B. N. 1947. Myxobacteria in soils and composts; their distribution, number and lytic action on bacteria. J. Gen. Microbiol. 1:1-10.

25. Voisard, C., Bull, C. T., Keel, C., Laville, J., Maurhofer, M., Schnider, U., Dèfago, G., and Haas, D. 1993. Biocontrol of Root Diseases by Pseudomonas fluorescens CHA0: Current Concepts and Experimental Approaches. Pages 67-89 in: Molecular Ecology of Rhizosphere Microorganisms. F. O'Gara, D. Dowling, and B. Boesten, eds. VCH, Weinheim, Germany.

26. Wensley, R. N. 1953. Microbiological studies of the action of some selected soil fumigants. Can J. Bot. 31:277-308.

27. Wilhelm, S., and Paulus, A. O. 1980. How soil fumigation benefits the California strawberry industry. Plant Dis. 64:264-270.

28. Wilhelm, S., Storkan, R. C., and Sagen, J. E. 1961. Verticillium wilt of strawberry controlled by fumigation of soil with chloropicrin and chloropicrin-methyl bromide mixtures. Phytopathology 51:744-748.

29. Yamanaka, S., Kawaguchi, A., and Komagata, K. 1987. Isolation and identification of myxobacteria from soils and plant materials, with special reference to DNA base composition, quinone system, and cellular fatty acid composition, and with a description of a new species, Myxococcus flavescens. J. Gen. Appl. Microbiol. 33:247-265.

30. Yuen, G. Y., Schroth, M. N., Weinhold, A. R., and Hancock, J. G. 1991. Effects of soil fumigation with methyl bromide and chloropicrin on root health and yield of strawberry. Plant Dis. 75:416-420. 